\title{
Town Staff's Model of Pension Insurance Fund Income in our Country and Empirical Research
}

\author{
Ya-Nan Shen \\ Harbin university of Commerce, Harbin, China \\ E-mail: Shenyn315@163.com
}

\begin{abstract}
The article summarized the structure of town endowment insurance fund income in our country, established actuary mathematical model of it and also gave the model of the population, wages and rate prediction under the policy of the delay retirement, using it to predict the future income of town endowment insurance funds in our country and providing effective theoretical basis for the analysis of endowment insurance gap.
\end{abstract}

Key words-Endowment insurance fund, Actuarial model, Prediction, Delay retirement.

\section{INTRODUCTION}

Due to the fact that the performation of part accumulation foundation of endowment insurance system in China was executed rather later, the cost of reform will be incapable to be digested in a short time, What's more, the channel for endowment investment is narrow, its income is low and population aging will come about quickly, endowment payment in future China will face enormous risks. In order to remain the sustainable and sound development of endowment insurance system and defend legal rights for the elderly and social stability, the actuary prediction of the scale and gap of payment balance of social endowment insurance in a long term has become our grave subject to be dealt with. The article analyzed the worker's mold of income of town endowment insurance funds in the policy background of retirement age.

\section{II.THE CONSTITUTION OF THE STAFF'S ENDOWMENT INSURANCE FUND INCOME IN TOWNS AND CITIES.}

Endowment insurance funds are divided into basic endowment insurance funds, annuity funds of the enterprise and personal saving endowment insurance funds. In the article, only relationship between basic endowment insurance funds and the number of staff and workers was considered. Basic endowment insurance fund revenue is divided into social pooling fund income and individual account funds. Social pooling funds perform the principle of pay-go and that part which belongs to individual funds adopts accumulation-made. As for endowment insurance in towns and cities which we researched, it included pooling funds and individual account funds as well. Pooling fund revenue includes contribution of employing units, national finance subsidy, local finance subsidy, the balance of fund interest and other revenue. Individual account fund revenue is that part which every endowment hands in according to the proportion of individual payment.

\section{THE ESTABLISHMENT OF STAFF'S ENDOWMENT INSURANCE INCOME MODEL IN TOWNS AND CITIES}

A long-term actuarial analysis of enterprise staff's endowment insurance is based on the prediction of the total population number and structure ,the population number and structure in towns and cities and the number of retired people and structure and the number of in-service staff's population who participates in endowment insurance and structure etc. In the meantime, it is necessary to make predictions about interest rates and economic development and so on. Endowment insurance fund income is estimately based on the prediction of future population, the future wages and the prediction of interest rates. It is made up of several interrelated models, that is to say, employment population model. The model of the in-service population who participates in endowment insurance, the model of average wage level and total wages, the model of interest rate etc. that is to say, endowment insurance income within one year is decided by in-service staff's population that participate in endowment insurance, wage level of average payment, defined and refused payment rate and establishes endowment insurance, estimated model-frame as follows. 


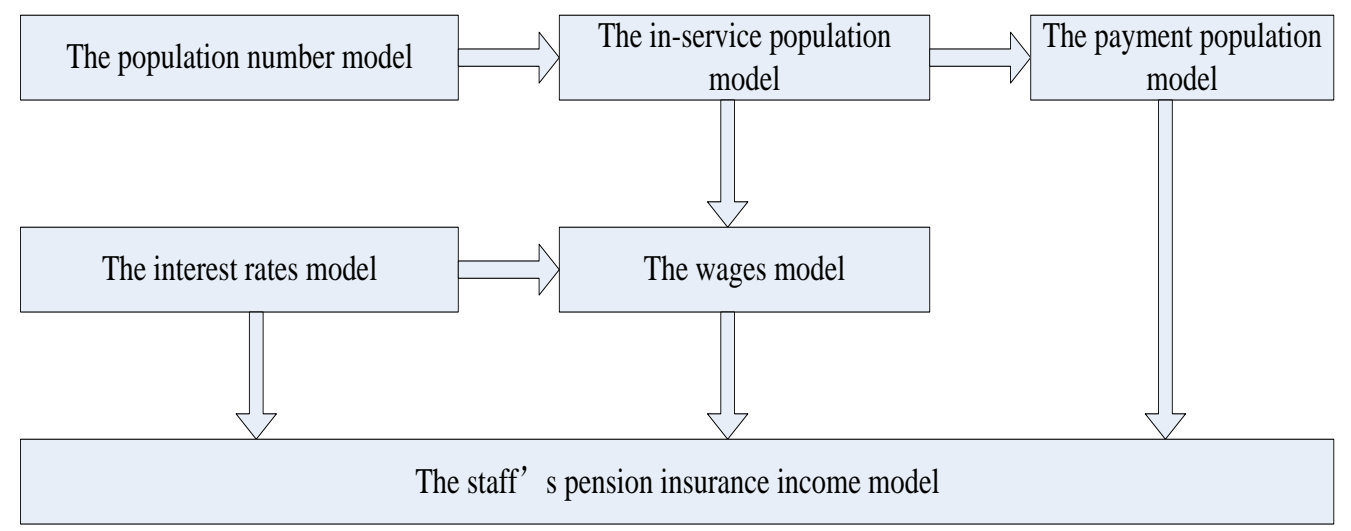

Figure.1. Model framework of endowment insurance income

Here is separately the model of staff's actually paid population prediction, the model of wage prediction and the model of interest rate prediction.

\section{A. Staff's Actually Paid Population Prediction in Towns and Cities}

Population policy is direct power which impacts demographic changes and is also a policy measure which a country takes as the population in it stops increasing or increases too fast and even appears negative growth. Different countries took different population policies because population development in one's own country is different. Population policy is vital component in basic national policies whether it is population policy expressly provided or not. Various guidelines and policies in the government have an influence on demographic changes. Furthermore, population policy in a country should adjust properly with the actual conditions of population development. Staff's actually paid employment. The coverage rate of endowment insurance, endowment insurance, ab-servant payment rate. Here we use $(s j)_{t, x}$ to represent $x$-year-old staff's actual paid population number in the year of $\mathrm{t},(c y)_{t, x}$ represent $x$-year-old staff's actual in-service population number in the year of it, $(z l)_{t, x}$ represent the observant payment rate of $x$-year-old staff's endowment insurance. So establishing the following relationship:

$$
(s j)_{t, x}=(c y)_{t, x} \cdot(z l)_{t, x} .
$$

Here in-service staff number is only divided into "new pensioner" and "middle pensioner". Therefore, we only consider the fund revenue that "new pensioner" and "middle pensioner" should pay.

\section{B. Wage increase rate and total wage prediction}

Wage growth rate mainly impacts endowment insurance fund income. When it changes, average wage level, total wages and endowment insurance yearly income will have the change of increase and decrease with it. Under the adjustment with different ways in retirement endowment, the increase and change of veal wage differently impact annual and long-term actuarial trimmed value. Growth rate of average social wage directly impacts the change of paid wage level, in turn impacts endowment insurance fund paid amount and endowment insurance payment and finally impacts the level and amount of endowment insurance payment and finally impacts the balance of endowment insurance funds. Use $\mathrm{A} g_{t}$ to represent average money wages in the year of $\mathrm{t}, A g l_{t}$ to increase rate of average real wage, $C P I_{t}$ to the increase rate of price index, $T g_{t}$ to total wages in the year of $\mathrm{t}, T s j_{t}$ to the number of the population that participates in endowment insurance, Then arose

$$
\begin{gathered}
T s j_{t}=\left\{\begin{array}{lr}
\sum_{x=15}^{n}(s j)_{t, x} \cdot(z l)_{t, x} & \text { female } \\
\sum_{x=15}^{m}(s j)_{t, x} \cdot(z l)_{t, x} & \text { male }
\end{array}\right. \\
\mathrm{Ag} g_{t}=A g_{t-1} \cdot\left(1+A g l_{t}\right) \cdot\left(1+C P I_{t}\right) \\
\boldsymbol{T g}_{t}=\boldsymbol{T S j}_{t} \cdot \mathbf{A g} \boldsymbol{g}_{t} .
\end{gathered}
$$

Including: $(s j)_{t, x}$ represent $\mathrm{x}$-year-old staff's real in-service paid population number, because of regarding launching new policy of delay retirement, $m, n$ in the formula separately represents the retirement age of male and female staff.

\section{Interest rate prediction}

Interest rate level is predicted according to price index and fund mean return, nominal interest rate gets rid of the affection of inflation factor and becomes actual interest rate. 
Using $\mathrm{M} l_{t}$ to represent nominal interest rate in the year of $\mathrm{t}, \mathrm{R} l_{t}$ to represent actual interest rate in the year of $\mathrm{t}$. Then arose:

$$
\begin{gathered}
1+\mathrm{R} l_{t}=\frac{1+M l_{t}}{1+C P I_{t}} . \\
1+M l_{t}=\left(1+\mathrm{T} l_{t}\right) \cdot\left(1+C P I_{t}\right)=1+\mathrm{T} l_{t}+C P I_{t}+C P I_{t} \cdot \mathrm{T} l_{t}
\end{gathered}
$$

Because actual interest rate and the growth rate of price index are both quite low, the above formula can nearly approximate:

$$
1+M l_{t} \approx 1+\mathrm{Tl}_{t}+C P I_{t}
$$

\section{Payment rate}

Payment rate means the rate of endowment insurance funds-collecting amount and total payment wage which belong to the payer in a company (enterprise and staff). Payment rate mainly means that it impacts the income aspect of endowment insurance fund. The leading factors which impact the fluctuation are endowment replacement levels and the population number of retired staff that needs to raise (dependency ratio). The two factors directly decide on the adjustment of payment rate. Payment rate is lower, payment income is fewer, thus it's adverse to the effectuation of balanced budget of endowment insurance funds, and even arises deficit in part. When payment rate is higher, payment income is more. Endowment insurance funds easily arises, therefore arises balanced budget of cash surplus in part. Confirming the change of payment rate is decided by payer, that is, the endurance of enterprise and staff. When payment rate is lower, payer endures the light burden in favor of the accumulation of the enterprise itself. When the payment rate of endowment insurance reduce and relieves the income of endowment insurance funds, we can make use of leverage to drive economic development by lightening the burden on enterprises. Payment rate is higher, the cost of production or operation on enterprises is higher and its burden is heavy, thus it is adverse to accumulation and development on enterprise. When accumulation and development on enterprises are restricted, the development level of the whole national economy is hard to rapidly improve and even the security level of the whole society is hand to improve. Therefore, confirming the level of payment rate is mainly considering endurance on enterprises. Because payment rate is too high, in turn impacts enterprises and economic development, it is sub-marginal.

\section{E. Retirement policy}

Retirement age generally means starting age of receive endowment benefit, so the policy of retirement age has a direct influence on endowment security system and is significant to the paying capacity of endowment. The elongation of retirement age means that the total time when the elderly receive endowment is shorter than before. While the time range when the elderly pay endowment insurance is longer. Like this, fund revenue will increase and payment will relatively decrease. As a result, it will benefit to the operation of pension insurance system and make the payment shock which endowment security system will face less in order to keep continuance and operation much easier. On the contrary, that retirement age is low means the time when the elderly receive their wage will be relatively extended, the time of paid insurance fee will be shortened and endowment insurance fund revenue will cut down and payment will relatively increase. And then it will enlarge the payment shock of endowment fund. As a result, its degree of difficulty continuance and operation will be extra large. Retirement age directly involves the amount of in-service staff number and retire number and impacts revenue and expenditure of endowment insurance funds system dependency ratios is called the rate of support, which refers to the number of staff and workers and the rate of the whole in-service endowment insurance in order to represent how many in-service staff every retiree is supported by? If retirement policy stipulates improvement at retirement age, the number of in-service staff joining in endowment insurance (payer) will be on the increase, the number of retirement staff (pensioner) will decrease, dependency ratios will decline and the heavy burden of social elder security will relieve so as to hedge the balanced budget of endowment insurance funds better.

Under the fixed condition of benefit level, the total sum of endowments which requires paying involves the population receiving endowments and the length of time receiving endowments. If retirement policy stipulates the reduction of retirement age, the number of in-service staff joining in endowment insurance will decrease, the number of retirement staff will increase, dependency ratios will increase, the burden of social elder security will be exacerbated. As a result, the age of employment is relatively stable, it is limited by years of education at school and the legal age of employment and so on and not easy to lower. The adjustment of retirement policy concerns payment shock of endowment and how the payment plan of endowment is correctly and reasonably restricted:

According to the alone factors, the mode of basic endowment insurance fund revenue in towns and cities can be set up and endowment insurance fund revenue will be divided into three parts: payment revenue, including contribution of the employing units and governments at all levels won't be regarded for the moment. Financing mode of endowment in China is part accumulation system. The accumulation refers to individual account pays expenses according to $8 \%$ of staff's basic wages last month and is undertaken by individual itself. Social pooling account still continues to use the system of charging and paying on hand and $20 \%$ of staff's basic wages last month are undertaken by enterprises.

Using $\mathrm{U}_{t}$ to represent the total revenue of staff's basic endowment insurance funds in towns and cities in the year of $\mathrm{t}, \mathrm{J}_{t}$ to basic endowment insurance payment revenue in the 
year of $\mathrm{t}, \mathrm{C}_{t}$ to basic endowment insurance payment rate in the year of $\mathrm{t}, \mathrm{Y}_{t-1}$ to balance fund of endowment insurance in towns and cities in the year of $\mathrm{t}-1, \mathrm{~W}_{t}$ to other revenues, $(f l)_{t}$ to actual coverage rate of staff's endowment insurance in towns and cities. Thus, the total revenue of staff's basic endowment insurance funds in towns and cities as follows

$$
\begin{aligned}
\mathrm{U}_{t} & =\mathrm{J}_{t}+Y_{t-1} \cdot\left(1+M l_{t}\right)+W_{t} \\
& =A g_{t-1} \cdot C_{t} \cdot(f l)_{t} \cdot T s j_{t}+Y_{t-1} \cdot\left(1+M l_{t}\right)+W_{t} \\
& =\left\{\begin{array}{lr}
A g_{t-1} \cdot C_{t} \cdot(f l)_{t} \cdot \sum_{x=15}^{n}(c y)_{t, x} \cdot(z l)_{t, x}+Y_{t-1} \cdot\left(1+M l_{t}\right)+W_{t} & \text { female } \\
A g_{t-1} \cdot C_{t} \cdot(f l)_{t} \cdot \sum_{x=15}^{m}(c y)_{t, x} \cdot(z l)_{t, x}+Y_{t-1} \cdot\left(1+M l_{t}\right)+W_{t} & \text { male }
\end{array}\right.
\end{aligned}
$$

\section{MODEL PREDICTION AND EMPIRICAL ANALYSIS}

\section{A. The assumption of model prediction.}

- The assumption of model prediction.

- The range of the model which is set up is from 2005 to 2055.

- $\quad$ The rate of contributors is $100 \%$

- Coverage rate is $100 \%$

- Average employment age is 22 years old, that is, new staff will join in the endowment insurance when obtaining employment.

- Average retirement ago is 57 years old (irrespective of sex)

- $\quad$ Social average wage in 2014 is 49969 yuan

- Retirement rate represents the ratio of the people who quit endowment insurance system due to all kinds of reasons.

According to the above analysis, we take interest rate as $3 \%$, retirement rate $1 \%$, wage growth rate $4 \%$ to calculate and draw as shown in Figure 2.

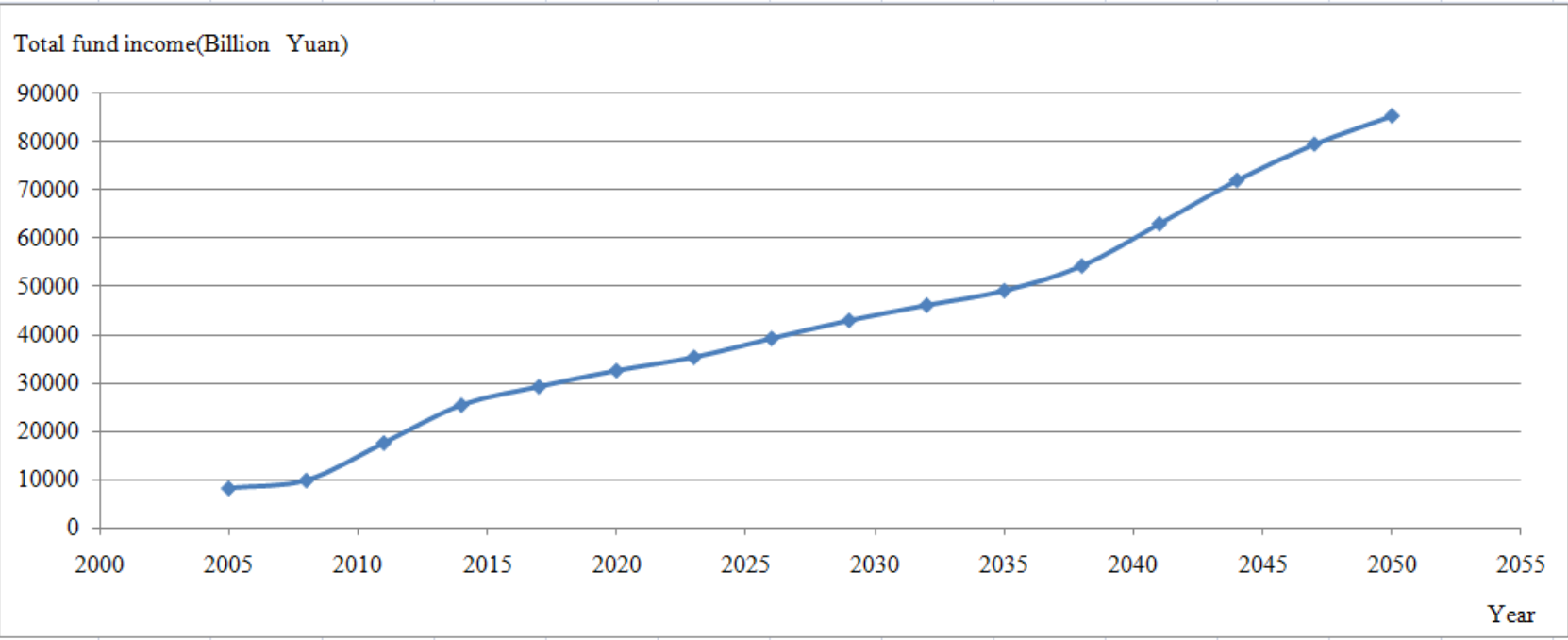

Figure.2. Model framework of endowment insurance income

\section{B. Model analysis and conclusion}

Endowment insurance fund income is sensitive to the change of surrender rate and wage growth rate. The total income of endowment insurance funds is inversely proportional to surrender rate. Wage growth rate is proportional to the total income of endowment insurance. With retirement age postponed, whether revenue of social policing fund or income of individual account funds, income tends to increasing trend. When surrender rate is higher, income will be lower, inspiration that when endowment insurance income is guaranteed, inspire people's positivity of joining in endowment insurance and try to improve people's life.

\section{ACKNOWLEDGEMENT}

This research was financially supported by the National Social Science Foundation under Grant 15BJL042.

The Planning Year Project of Heilongjiang Province 


\section{Philosophy Social Sciences Research under Grant 16TJC01}

\section{REFERENCES}

[1] Xiao Huang, Li Shi, "Evolution analysis of endowment fund revenue “, Statistics and Decision, vol.13, 2006.

[2] Jia Xu, Xinping Fu, Steve.Peng, Chunhua Zhou, Zhuqiao Gao, "Construction of the new policy endowment fund revenue and expenditure model”, Statistics and Decision, pp.65-67, Oct. 2007.
[3] Yujian Shi, Basic endowment insurance fund actuarial study workers, Shandong Normal University, 2013.

[4] Hongjun Miao, Chinese urban workers to delay retirement research, Liaoning University, 2011.

[5] Tieying Feng, Fang Liu, "Prediction of ability to pay for urban enterprise employees' basic endowment insurance fund", Northwest population, pp. 10-17, Feb. 2010. 